\title{
Can physicians prevent post-lumbar puncture headache or intracranial hypotension?
}

Lumbar puncture (LP) is an essential procedure applied for mostly diagnostic and sometimes therapeutic purposes. It is also necessary to measure the cerebrospinal fluid (CSF) biomarkers for determining the prognosis in some neurodegenerative and neuroinflammatory diseases. ${ }^{[1,2]}$ However, it may lead to some complications such as post-lumbar puncure headache (PLPH) as commonly found. Furthermore, some cases suffering from headaches due to CSF leakage after LP for years have been reported. ${ }^{[3]}$

Although the exact mechanism of PLPH or post-dural puncture headache (PDPH) is not accurately known, various theories are available. These theories are mostly based on the loss of CSF volume. The most common theory is the occurrence of headache by pulling down of pain-sensitive structures after upright position due to CSF volume loss. The other theories are compensatory vasodilation of the intracranial arteries for maintenance of intracranial volume (Monroe-Kellie doctrine) and hypersensitivity to substance $\mathrm{P}^{[4,5]}$ Excellent results with epidural blood patch, especially if applied early in the course of PLPH, can be considered as proof of the CSF leakage. ${ }^{[3]}$ In the study by Özdemir et al., observation of intracranial hypotension with non-angular needle deformities is compatible with that idea also. ${ }^{[6]}$ It is thought that blood patch pretending as gelatinous tamponade in the epidural space allows healing of the needle hole normally and prevents CSF leakage. ${ }^{[3]}$

Attention to procedure-related factors during LP may reduce the risk of PLPH. Operation-related risk factors for PLPH includes: (1) Equipment-related factors (needle type, size and shape); (2) procedure-related factors (bevel orientation, angle of insertion, stylet replacement); and (3) other factors such as operator experience. ${ }^{[7]}$

\begin{tabular}{|l|l|}
\hline \multicolumn{2}{|c|}{ Access this article online } \\
\hline Quick Response Code: & Website: \\
\hline & www.ruralneuropractice.com \\
\cline { 2 - 2 } & \\
\hline & \\
\end{tabular}

Although there are some other factors to cause PLPH, it is important to not ignore procedure-related factors. However, there are few studies on this issue. The study by Özdemir et al. is important in this regard. ${ }^{[6]}$ In their report, procedure-related causes of PLPH were main themes as beside the other risk factors. Considering the frequency of difficulties during LP in our daily practice, importance of procedure-related factors may be seen more clearly. In a study by Shah et al., LP were scaled as difficult (with requirement of 3 or more needlesticks, or requirement of a second clinician to complete procedure) in 47 (32\%) out of 148 patients. In the same study, LP was traumatic in $16 \%$ of the patients. ${ }^{[8]}$

Özdemir et al. investigated the relationship between needle deflection occurred during LP and PLPH, interestingly. ${ }^{[6]}$ The authors reported that although there were no correlation between the needle deflection and PLPH, intracranial hypotension was present in the patients with non-angular needle deformities. Thus, we may speculate that, this complication may be prevented in some degree if attention would be paid to procedure-related factors. The authors proposed to continue LP with a new needle if the needle axis deviated.

Additionally, considering the importance of the LP in medicine, studies on preventing LP complications are essential and may be expected to remain helpful in the future also.

Sevim Şahin

Department of Pediatric Neurology, Karadeniz Technical University, Trabzon, Turkey

Address for correspondence: Dr. Sevim Şahin,

Department of Pediatric Neurology, Karadeniz Technical University, Farabi Cad., Trabzon - 61000, Turkey. E-mail: sevimsahin1@yahoo.com

\section{References}

1. Davis A, Dobson R, Kaninia S, Espasandin M, Berg A, Giovannoni G, et al. Change practice now! Using atraumatic needles to prevent post lumbar puncture headache. Eur J Neurol 2014;21:305-11. 
2. Gunnarsson M, Malmeström C, Axelsson M, Sundström P, Dahle C, Vrethem M, et al. Axonal damage in relapsing multiple sclerosis is markedly reduced by natalizumab. Ann Neurol 2011;69:83-9.

3. Harrington H, Tyler HR, Welch K. Surgical treatment of post-lumbar puncture dural CSF leak causing chronic headache. Case report. J Neurosurg 1982;57:703-7.

4. Bezov D, Lipton RB, Ashina S. Post-dural puncture headache: Part I diagnosis, epidemiology, etiology, and pathophysiology. Headache 2010;50:1144-52.

5. Grant R, Condon B, Hart I, Teasdale GM. Changes in intracranial CSF volume after lumbar puncture and their relationship to post-LP headache. J Neurol Neurosurg Psychiatry 1991;54:440-2

6. Özdemir HH, Demir CF, Varol S, Arslan D, Yildız M, Akil E. The effects of needle deformation during lumbar puncture. J Neurosci Rural Pract 2015;6;198-201.

7. Bezov D, Ashina S, Lipton R. Post-dural puncture headache: Part II-prevention, management, and prognosis. Headache 2010;50:1482-98.

8. Shah KH, McGillicuddy D, Spear J, Edlow JA. Predicting difficult and traumatic lumbar punctures. Am J Emerg Med 2007;25:608-11.

How to cite this article: Sahin S. Can physicians prevent post-lumbar puncture headache or intracranial hypotension? J Neurosci Rural Pract 2015;6:131-2.

Source of Support: Nil. Conflict of Interest: None declared.

\section{"Quick Response Code" link for full text articles}

The journal issue has a unique new feature for reaching to the journal's website without typing a single letter. Each article on its first page has a "Quick Response Code". Using any mobile or other hand-held device with camera and GPRS/other internet source, one can reach to the full text of that particular article on the journal's website. Start a QR-code reading software (see list of free applications from http://tinyurl.com/ yzlh2tc) and point the camera to the QR-code printed in the journal. It will automatically take you to the HTML full text of that article. One can also use a desktop or laptop with web camera for similar functionality. See http://tinyurl.com/2bw7fn3 or http://tinyurl.com/3ysr3me for the free applications. 